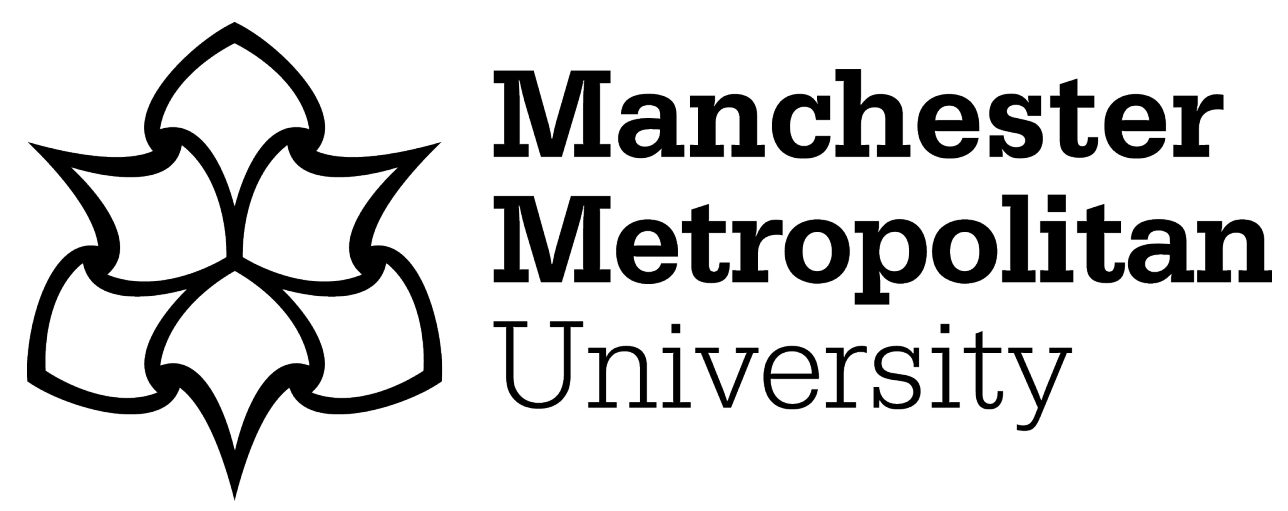

Nwakasi, CC, de Medeiros, K and Bosun-Arije, FS (2021) "We Are Doing These Things So That People Will Not Laugh at Us": Caregivers' Attitudes About Dementia and Caregiving in Nigeria. Qualitative Health Research, 31 (8). pp. 1448-1458. ISSN 1049-7323

Downloaded from: https://e-space.mmu.ac.uk/628331/

Version: Accepted Version

Publisher: Sage

DOI: https://doi.org/10.1177/10497323211004105

Please cite the published version 


\title{
"We Are Doing These Things So That People Will Not Laugh at Us": Caregivers' Attitudes About Dementia and Caregiving in Nigeria
}

\author{
Candidus C. Nwakasi' (iD, Kate de Medeiros², and Foluke S. Bosun-Arije ${ }^{3}$
}

\begin{abstract}
Some Nigerians, in their effort to make sense of dementia symptoms, use descriptions that may stigmatize people with dementia and their families. This qualitative descriptive study focused on the everyday understanding of dementia and the impact of stigma on the caregiving experiences of informal female Nigerian dementia caregivers. Semi-structured interviews were conducted with a purposive sample of 12 adult informal female caregivers in Nigeria and analyzed for themes. Afterward, results were presented to focus groups of 21 adult Nigerians residing in the United States for more contextual insight on the findings. The three major themes were misconceptions about dementia symptoms, caregiving protects against stigmatization, and stigma affects caregiving support. Overall, we argue that knowledge deficit, poor awareness, and traditional spiritual beliefs combine to drive dementia-related stigmatization in Nigeria. Strategies such as culturally appropriate dementia awareness campaigns and formal long-term care policies are urgently needed to help strengthen informal dementia caregiving in Nigeria.
\end{abstract}

\section{Keywords}

mental health and illness; youth, young adults, older people; aging, home care; caregivers, caretaking, religion, spirituality; culture, cultural competence, dementia, health seeking; health, access to; health care, immigrants, migrants; qualitative descriptive research; Nigeria

\section{Introduction}

Like most countries, Nigeria is experiencing rapid population aging and an increase in the prevalence of Alzheimer's disease (AD) and related dementias (hereafter referred to as dementia; Ballard et al., 2011; Kalaria et al., 2008; Sosa-Ortiz et al., 2012). The pooled prevalence of all dementias in Nigeria from 1990 through 2018 was estimated at $4.9 \%$, with men showing higher rates (6.7\%) compared with women $(3.9 \%$; Adeloye et al., 2019). According to George-Carey et al. (2012), dementia prevalence likely doubles every 5 years after age 65 , which will lead to increases in Nigeria as the population ages. In addition, like other Sub-Saharan African (SSA) countries, this increasing prevalence is not matched with increasing scientific knowledge and awareness about dementia (Brooke \& Ojo, 2019; Spittel et al., 2019), but rather remains grounded in folk or everyday beliefs (Kleinman, 1978) coupled with reliance on unpaid caregivers (Schatz \& Seeley, 2015). Subsequently, Nigeria also shares some similarities to other SSA countries in that dementia carries stigma for people living with dementia and their families because some believe that dementia is a punishment for transgressions earlier in life or is caused by witchcraft (Brooke \& Ojo, 2019; Spittel et al., 2019; Yusuf \& Baiyewu, 2012). To complicate matters, family members of persons with dementia risk being ostracized by others, including other family members, because of these beliefs (Adebiyi et al., 2016).

Although there is literature on some of the challenges of familial caregiving in Nigeria (e.g., Nwakasi, 2019; Ogunniyi et al., 2005; Okoye, 2012, 2014; TogonuBickersteth \& Akinyemi, 2014), it is unclear how

\footnotetext{
'Providence College, Providence, Rhode Island, USA

${ }^{2}$ Miami University, Oxford, Ohio, USA

${ }^{3}$ Manchester Metropolitan University, Manchester, United Kingdom

Corresponding Author:

Candidus C. Nwakasi, Department of Health Policy \& Management,

Providence College, I Cunningham Square, Providence, RI 02918-

7000 , USA.

Email: cnwakasi@providence.edu
} 
caregivers in Nigeria navigate difficulties such as social stigma related to dementia reported by other Nigerian studies (see Adebiyi et al., 2016; Faleye, 2017). The purpose of this study, therefore, was to gain a deeper understanding of the likely impact of stigma on caregiving experiences through in-depth interviews with women who identified themselves as dementia caregivers. The overarching goal was to gain a deeper knowledge into the "everyday" or common-sense understandings that laypeople use to make sense of dementia in contrast to specialized, scientific, or clinical understandings (Kleinman, 1978; Kleinman \& Good, 1985). We begin with a brief section on Nigeria's health system and access to dementia care, followed by cultural and informal caregiving, and stigma related to dementia in Nigeria.

\section{Nigeria's Health System and Accessing Dementia Care}

Nigeria has the largest population of older adults $(60+$ years) compared with other SSA countries (Velkoff \& Kowal, 2006; Zaney, 2018). In 2015, around 5.6 million Nigerians were aged 60 and above. Demographers project an increase to 18.8 million by 2050 (He et al., 2016). Until now, Nigeria's high fertility rate has masked the growth in older persons. Consequently, issues affecting older people, such as increased risk of dementia with advancing age, have been largely overlooked (Velkoff \& Kowal, 2006). These demographic changes bring attention to the need for a strengthened health system, especially with regard to dementia given both the increased risk of disability and dependency of people living with dementia, and the increased risk of poverty and poor health of their families who provide care and support (George-Carey et al., 2012).

Although there are no studies to our knowledge on the effect of Nigeria's weak health system on dementia care, we can make informed speculations given the current state of mental health care. We note that the concept of "mental health" is embedded in health care and cultural systems (Kleinman, 1978). Nigeria's health system is underfunded, and it is characterized by health inequity and poor access to health care, particularly for those in rural areas where most older Nigerians reside (George-Carey et al., 2012; Welcome, 2011). About $80 \%$ of people with mental health needs cannot access care due to inadequate resources and negative cultural attitudes about mental disorders reinforced by an outdated/ineffective mental health legislation (Ugochukwu et al., 2020). Abdulmalik et al. (2019) argued that the estimated budget line for mental health in the country's annual national health budget has been consistently abysmal $(<3.5 \%)$. This may explain the scarcity of mental health workers (e.g., nurses, social workers, psychologists, doctors, occupational therapists, psychiatrists), which is 0.9 per 100,000 Nigerians, and poor mental health financing (mostly out of pocket; see World Health Organization, 2014). Another explanation is likely the widely held perception that mental health disorders are caused by supernatural factors (e.g., evil spirits) or God's will/punishment (Labinjo et al., 2020). With these health system challenges, it is unsurprising that long-term care, especially dementia care, in Nigeria depends mainly on informal caregivers.

\section{Cultural and Informal Caregiving}

Like in many places, families in Nigeria are structured such that older adults are supported by their adult children and relatives (Ogunniyi et al., 2005; TogonuBickersteth \& Akinyemi, 2014); women and girls provide the overwhelming majority of direct care while men are more likely to provide financial support for the family (Okoye, 2012; Uwakwe, 2006). Even if long-term care was available, accessible, and affordable, which it currently is not, utilizing formal long-term care such as nursing homes is not culturally acceptable. Families who access the few formal long-term care services available are typically frowned upon (Okoye, 2012).

In addition, in Nigeria, although caring for a person living with dementia who may be exhibiting associated symptoms (e.g., inappropriate language, aggression) can be difficult, caregivers rarely seek external or professional help. This is likely due to problems with health care access and the unacceptance of formal long-term care mentioned earlier (Ogunniyi et al., 2005; Okoye, 2012; Welcome, 2011), as well as the stigma associated with dementia (Adebiyi et al., 2016; Brooke \& Ojo, 2019; Nwakasi et al., 2019; Spittel et al., 2019). As a result, care for people living with dementia in Nigeria is assumed to be substantially worse compared with developed countries (Ogunniyi et al., 2005). To further complicate matters, many adult children on whom families depend for care are also undergoing economic hardships such as unemployment (Akinyemi, 2014; Okoye, 2014), which can add to the stress of providing care.

\section{Stigma and Dementia in Nigeria}

Stigma was described by Goffman (1963) as the experience of shifting from "a whole and usual person to a tainted, discounted one" (Goffman, 2006, p. 131) by having what he calls "an attribute that is deeply discrediting" (p. 132) or a spoiled identity. The stigmas related to dementia may be based on culturally grounded prejudice and/or "everyday" or lay understandings about the origins of a particular condition (Kleinman \& Good, 1985). Regardless, its effects are long lasting, even with increased education and transformation of cultural features that initially created 
the stigma (Pescosolido \& Martin, 2015). Stigma surrounding dementia has been reported in numerous cultures and group and affect not only the person living with dementia, but their caregivers as well (Dilworth-Anderson \& Gibson, 2002; Liu et al., 2008).

In Nigeria, there is no word for dementia in its approximately 520 local spoken languages. This has led to misunderstandings about dementia and the stigma of living with dementia. For example, words such as "madness," "witchcraft," and "unintelligent" are often used to describe dementia symptoms (Adebiyi et al., 2016; Ogunniyi et al., 2005). Some may also believe that dementia symptoms are a type of punishment for actions performed earlier in life, are due to witchcraft or sorcery, or a part of normal aging (Berwald et al., 2016; Gurayah, 2015; Khonje et al., 2015; Nwakasi et al., 2019). Uwakwe (2000) conducted a study in Anambra state, Nigeria, on the relationship between dementia patients' withdrawal from formal treatment and the influence of religious ministers on specialized dementia care seeking. He reported that all 10 religious leaders interviewed believed dementia is caused by evil spirits and nine did not believe orthodox medical practice was useful for those living with dementia. As such, people living with dementia may be blamed and stigmatized for their condition, resulting in lack of caregiver empathy and poorer care, and fears of caregivers being stigmatized themselves (Nwakasi, 2019).

In addition, a systematic review identified religious/ spiritual belief as a driving force for dementia-related stigma in Nigeria and eight other African countries, even among highly educated Nigerians and medical professionals (Spittel et al., 2019). Witchcraft, Satanism, evil spirit, and "punishment from God" were considered to be causes of stigmatization of people living with dementia, resulting in them being treated as downgraded members of the community (Adebiyi et al., 2016).

Even for some older Nigerians and those yet to be categorized as older adults, lack of accurate information on dementia has led to increased fear and anxiety about getting old (Wahab \& Ikebudu, 2014). Further, a study by some Nigerian researchers found that in the country, people avoided marrying into families where dementia was present, an avoidance that not only affected current generations, but future ones as well (Adebiyi et al., 2016). Among their respondents $(n=211)$, more than $36 \%$ reported they would be ashamed to have dementia and hoped outsiders would not be aware of their condition, $30 \%$ thought that people living with dementia are not to be taken seriously, and $17 \%$ believed people living dementia should not be allowed to interact with people in the community. Given these and other potential social pressures to keep dementia hidden, it is extremely important to learn more about caregivers' attitudes about dementia and caregiving if effective changes that would benefit people living with dementia are to be made.

\section{Method}

We used a qualitative descriptive research approach to explore the everyday understanding of dementia and how stigma affected the caregiving experiences of informal female Nigerian dementia caregivers. Unlike other qualitative approaches (e.g., grounded theory, phenomenology) that are deeply embedded within theoretical, philosophical, and/or discipline-based frameworks, a qualitative descriptive approach is purely data-derived (V. A. Lambert \& Lambert, 2012). This approach is applicable for a research that focuses on capturing the who, what, and where of events/experiences without pre-selection of variables or the goal of producing a theory. This approach, therefore, results in a straightforward description of a particular phenomenon (Kim et al., 2017; Sandelowski, 2000).

The research team consisted of three people: the lead researcher, who is a Nigerian but currently residing in the United States; a dementia research expert in the United States; and an on-the-ground research person in Nigeria. In addition, a gateway consultant, who was a senior registered nurse at a geriatrics outreach center, facilitated participant recruitment. Following is a description of our research steps.

\section{Sampling Strategy for the Interviews}

Twelve (12) participants were recruited using a purposive sampling method (see Table 1) from Anambra state, an area with a population of over 4 million located in the southeast of Nigeria (Brinkhoff, 2017). While the majority of people in Anambra identify as Christians, some still hold on to their "Odinani" (traditional beliefs). The inclusion criteria were as follows: female who identified as a caregiver for at least 6 months; at least 21 years of age; resident of Anambra, Nigeria; and able to complete a telephone interview in English. Most of the recruited participants were Igbos. The gateway consultant contacted potential participants, family members of persons with dementia who had received care from her geriatrics outreach center, briefly explained the study, and asked for the person's permission to forward contact information to the researcher in Nigeria. A letter of support from the geriatric outreach center was obtained prior to the start of the research and was submitted to the institutional review board of Miami University of Ohio, which approved the study (approval number: 02990e). The on-site researcher in Nigeria then contacted potential participants (dementia caregivers), met them at a venue of their choice, screened them to ensure they met the inclusion criteria, provided study details, and asked for further permission to forward 
Table I. Demographic Characteristics of Participating Caregivers.

\begin{tabular}{lcllll}
\hline $\begin{array}{l}\text { Number of } \\
\text { Participants }\end{array}$ & Age (Years) & Marital Status & Education & Occupation & $\begin{array}{c}\text { Resides With Person } \\
\text { With Dementia }\end{array}$ \\
\hline I2 Women & $32-76$ & 8 Married & 8 Tertiary & 2 Retired & I0 Yes \\
& & I Widow & 4 High School & 5 Employed & I No but visits daily \\
& & & & 4 Small Business Owner & I No but visits monthly \\
& & & & I Unemployed & \\
\hline
\end{tabular}

Note. Mean age $=48.9, S D=13.32$.

their contact information to the lead investigator for a telephone interview. Prior to the start of an interview with participants, the lead researcher answered study questions and obtained verbal consent. Pseudonyms are used for the participants.

\section{Data Collection}

\section{Interviews}

The lead researcher conducted semi-structured telephone interviews to give participants a greater assurance of anonymity (see Table 3 in supplemental files). All interviews were conducted in English and were audio-recorded with the participant's permission. When required, the lead researcher probed participants' responses for clarification. Interviews, which lasted approximately 1 hour each, were transcribed verbatim. Potential identifiers were removed to protect participants' identity.

In addition to the interviews, written memos helped the lead researcher to stay connected with the objectives of the study by allowing the research to identify key concepts in the raw data and areas that required further investigation in subsequent interviews (Birks et al., 2008). Memos also helped to make meaningful interpretations of participants' views as the researcher was able to record non-verbal expressions (e.g., anger, frustration, laughter, change in vocal tone, reluctance to respond). Field notes from the study included helpful suggestions from the gateway consultant and members of the research team during the data collection phase. Data collection was discontinued when it seemed like data saturation, or the point at which no new information or insight was being provided, was reached (Fusch \& Ness, 2015).

\section{Data Analysis}

Dedoose (version 4.3), a qualitative research software, was used for data management and analysis. We used thematic analysis for the data analysis. The development of codes and themes using this approach involved a repetitive process informed by Braun and Clarke (2006) and Bryman (2012). The interview transcripts and field notes were carefully read and re-read for familiarity with the data. This phase led to the development of a code manual containing broad codes and to help provide a trail of evidence of the study (Fereday \& Muir-Cochrane, 2006). The initial codes were formed after identifying features such as words and phrases that were relevant to the research aim. Afterward, we examined co-existing codes or codes with high usage counts to identify emerging patterns, which composed our themes. The emerging themes were reviewed to ensure they were germane to the research question and objectives. We later defined themes, looked for supporting and conflicting examples, and revised themes as necessary until we agreed that the themes were compelling and unique.

\section{Trustworthiness}

To ensure rigor and achieve trustworthiness of our findings, we used four approaches. First, we used an audit trail whereby the researcher kept detailed descriptions of the data collection and analysis techniques used (e.g., codebook used during the data analysis; Lietz et al., 2006). Second, we also conducted peer debriefing (Hadi \& Closs, 2015; Hamilton, 2020) which involved regular meetings with a skilled qualitative researcher to discuss the research techniques, the data collection and analysis, and findings as they unfolded. Third was reflexivity (see Hadi \& Closs, 2015). The primary researcher used personal reflections and field notes to identify and manage potential biases. This is important because of the lead researcher's cultural similarity with the participants. It is equally important to note that the cultural similarities helped the researcher identify areas during the interview that merited more probing.

Finally, as it was not possible to complete member checking given the distance and the potential stigma associated with dementia caregiving in Nigeria, we strengthened the trustworthiness of the study by presenting key findings to four focus groups (FGs) composed of Nigerians living in the United States for their interpretation and input. According to S. D. Lambert and Loiselle (2007), interviews and FGs can be combined to ensure data completeness and/or confirmation. The focus group 
Table 2. Profile of Focus Group Participants $(N=2 I)$.

\begin{tabular}{ll}
\hline Number of focus groups & 4 groups: \\
& 2 male groups ( 3 in one group, 4 in the other), \\
& 2 female groups (4 in one group, I0 in the other group). \\
& 7 men; I 4 women \\
Gender & Men: $33-43$ years of age $(M=36.7, S D=3.73)$ \\
Age & Women: \\
& Ist Group ( 4 women; $29-4$ I years of age, $M=32.8, S D=5.68)$ \\
& 2nd Group (While ages of most participants were not available, the youngest was 29 years and the \\
& oldest was 59 years) \\
& They all had tertiary level/above high school education
\end{tabular}

discussion (FGD) offered an opportunity to examine attitudes, opinions, and beliefs about a phenomenon that were mentioned in individual interviews (Birt et al., 2016; S. D. Lambert \& Loiselle, 2007)—by a group who were likely familiar with everyday understanding of dementia and caregiving expectations but who were physically and socially distanced from the participants. Therefore, the purpose of the FGs was to let the research team know if their findings "rang true" or made sense in the context of caregiving in Nigeria. In addition, the research team believed that the FGs may provide additional interpretive insight into what the female caregivers said given the FG members' cultural similarity with the caregivers in Nigeria.

FGs were composed of 21 people (seven men and 14 women) who were recruited through snowball sampling (i.e., they were recruited with the help of those who had been recruited). Inclusion criteria for the FGs were as follows: an adult who lived in Nigeria for 20 or more years; from the same general areas where the dementia caregivers lived (southern Nigeria); and ability to communicate in English. Most of the recruited FG participants were Igbos, the main ethnicity of those in the southeastern part of Nigeria including Anambra state and therefore shared cultural similarities with the dementia caregivers. All recruited FG members had post-high school (tertiary) education and were working in the United States. All provided informed consent to participate in the study. Table 2 contains a profile of the FG participants.

\section{FG Procedure}

The first FG included three men, the second included four women, the third included four men, and the fourth FG included 10 women. The lead researcher, as the moderator, organized the FG sessions, which were held at locations that were convenient for all FG participants involved. Three of the four FGDs were conducted face-to-face. One was conducted over a telephone conference call. All the discussions were in English, audio-recorded, and transcribed verbatim with consent of the FG participants. We note that the FG were gender separate to reduce bias by allowing participants to feel comfortable sharing their views without worrying about how those from the oppositive gender might react. The lead researcher asked semi-structured questions with the help of an interview guide (see Table 4 in supplemental files) based on the findings from the interviews. FGs lasted around 1 hour. The same data analytical approach used for the data collected from interviewing the caregivers was used to analyze the FG data.

\section{Findings}

We identified three themes: misconceptions about dementia symptoms, caregiving protects against stigmatization, and stigma affects caregiving support. Each theme is described below and includes observations by some of the FG members.

\section{Theme I: Misconceptions About Dementia Symptoms}

Overall, as the research literature suggested, participants associated dementia symptoms with normal aging, witchcraft or sorcery, or "madness." One of the participants (Chika) attributed dementia to normal aging but also expressed her difficulty to make sense of the condition. She said, "I call it age; I call it age because I don't know what to call it." Similarly, Mary said, "It is an illness or behavior, certain old or middle age people experience when they are getting old." Bola's views were somewhat different. She explained that some people in her community saw her father's condition as part of normal aging but added that his condition is just a sickness, given that other people who are older than him can still lead normal lives without cognitive issues.

In addition, some participants described dementia symptoms by associating them with witchcraft and sorcery. Bola said, "You know in the village; they will think that somebody is bewitching [or casting evil spell on] that person [with dementia]. They don't know it is 
a sickness.” As suggested with Bola's different views, perceptions about dementia symptoms could be conflicting. For example, Esther commented, "Some people are saying somebody [sorcerer/witch] is trying to manipulate her [person with dementia]. Others are saying it is what she did when she was young that is affecting her." In this way, persons with dementia may be viewed as victims of sorcery or as mentioned in the introduction, victims of their own previous evil deeds.

Mary believed people in her community who do not have adequate information about dementia may view a person with dementia as "mad." This was similar to the views shared by other participants. For example, Rita told the interviewer: "She [her grandmother with dementia] was back there in the village and the thing [symptoms] was starting. They [the villagers] called me asking and saying if it is madness that is happening to my grandma." She added that she found the villagers' attitude toward her grandmother to be very hurtful.

In commenting on this theme, the FG members offered insight on views of dementia symptoms described by the caregivers. Most of the FG members believed that poor dementia awareness in Nigeria is responsible for people associating dementia symptoms with sorcery and madness. For example, a male FG member said, "It can be defined as a mental disorder, but saying it is 'madness' is ignorance." Another FG participant (male) described how culture influences the way people make sense of dementia symptoms in Nigeria. He said,

The African culture is vast, and there's a lot of mix up and complications with mental health and sorcery. Culture plays an important role here [in Nigeria]. Some people think there's no natural illnesses. It [dementia] could be as a result of karma or someone trying to get at you.

The above statement indicates that the participant believed that African culture helps to describe any phenomenon that is poorly understood as a likely spiritual issue. He further added that these culturally influenced views are why "People will start to go to the church to seek for miracle, or to go to a native doctor [traditional healer] to get a cure, saying it [dementia] could be madness or a spell."

\section{Theme 2: Caregiving Protects Against Stigmatization}

Some of the participants felt that being caregivers helps to protect the person with dementia and other members of the family from outsiders' negative attitudes. One of the participants (Mary) said, "It's [having dementia] like somebody that is mentally retarded. You don't want people to talk about it. It [the person with dementia] requires special attention and protection." She further described, "We are doing these things [caregiving] so that people will not laugh at you [us]. They will not have a prejudiced view of the family, so you have to cover everything." Mary's comment suggests that an important aspect of caregiving is protection of the family from shame or discrimination. This is similar to another caregiver's comment about her grandmother with dementia. She (Rita) said, "Since she is my grandmother and people see her as a mad person, I don't like it. So, I prefer to stay at home and take care of her than leaving her that way [unattended]."

For some participants, the quality of care provided can make a difference on how the person living with dementia is viewed. Thus, good care may help prevent negative, possibly stigmatizing views. This might be achieved by maintaining the dignity of the person living with dementia at all times, which may also help keep the person's condition undisclosed. This was explained by Daniela:

I always make sure I use Dettol [sanitizer/deodorizer] to clean the room where I kept her [mother with dementia]. If you see her that time, if you see my mum, you won't even know that she is having dementia. After dressing her, I will clothe her very well, use perfume. I will use perfume on her. I will even wear her trouser, and if you see her you won't even know that she is having such sickness.

Maintaining hygiene (e.g., incontinence, overall cleanliness) not only comprised good care but also masked some of the challenges associated with living with dementia, such as toileting and dressing.

FGs added to the insight on this theme by sharing their views on how protection against stigma may be a motivation for dementia caregiving. According to some of the FG members, caregivers may lie about the older adult's health/medical condition. For example, saying the person "has malaria" instead of dementia, in addition to keeping the person away from the public. The impact of the stigma from dementia is also believed to affect important social aspects (e.g., marriage) of family members of a person living with dementia. A female FG member said,

. . You know how it is in Nigeria. If someone is mad [dementia] in a family, they [outsiders] will see it as one person [a younger family member] is going to be mad in your family. They won't want to marry you, and they will say_ “oh this person's grandma was mad, don't marry from that family. They have mental illnesses in that family."

Some of the FG members also thought that dementiarelated stigma resulted from poor dementia awareness. One of the FG (female) members said, “. . . it's possible that it [dementia] is popular [common in Nigeria]. It's just that everyone is hiding their shame per se." In this way, she suggests that although several families may 
have persons with dementia in the community, most are hiding it from the public to prevent the possible stigmatization of their families.

\section{Theme 3: Stigma and Caregiving Support}

The participants shared that dementia attitudes can influence support for caregivers. According to the caregivers, the availability of familial and sometimes, community supports that are assumed to be available for female caregivers in Nigeria are affected by how people make sense of dementia symptoms. One of the participants (Gina) described how being viewed as a witch can result in adverse consequences. She said, "It [dementia] is the reason people are not greeting her [mother with dementia]. My brother stopped coming home, even stopped giving her money [financial support]." Gina's eldest brother and wife believed Gina's mother was a witch and subsequently dissociated themselves from her, thus affecting the quality and amount of caregiving support available for her mother. Nene, who had two adult daughters stated that the daughters do not help with caregiving because they do not want to be associated with their father's condition. Nene added that she sought assistance from her church members (Christians), but they only offered to "take him [husband with dementia] to those people that worship idol [traditional healers]" to cure his mystical condition.

Another caregiver, Esther, a registered nurse who wanted to periodically share caregiving responsibilities with her family members said, "I am planning in my mind to tell them [about sharing caregiving duties] when they come back this December [for the Christmas celebration]. Because locking her up, you don't know what will happen." Esther's comment suggests she is worried about what might happen to her family member who is left physically isolated without supervision.

Regarding this theme, most of the FG members believed some of the issues surrounding poor caregiving support were connected to negative attitudes about dementia. A female FG member described how she had to convince her sister that their father with dementia is not a witch/wizard and of the importance of coming together as a family to care for him. Another FG member (male) thought attributions such as "sorcery" allowed some family members to escape the responsibility of providing caregiving support. Another FG member talked about caregivers' inability to access adequate family support because of dementia-related stigma. She explained,

This issue of the dementia patient being stigmatized also comes from the family members which now makes it even worse-because a family that has about 5 people, and out of the 5, 3 people are not even OK with the fact that this [dementia occurrence in the family] is going on, then you're left with just two people to deal with [provide caregiving support] what is going on. What 5 people should have been able to do; it breaks everybody down especially the caregivers.

\section{Discussion}

This study explored perceptions of dementia and stigma on the caregiving experiences of informal female Nigerian dementia caregivers. Overall, we found that misconceptions about dementia symptoms, which are deeply rooted in everyday understandings of dementia causes resulted in stigmatization, thereby compounded the challenges of caregiving (Benbow \& Jolley, 2012; Kleinman \& Good, 1985; Urbańska et al., 2015). In the Nigerian context, the study findings shed light on how some lay understandings about dementia symptoms (e.g., "madness," "insane," "crazy") and stigmatization are linked. Findings are also in line with some Nigerian studies (see Adebiyi et al., 2016; Faleye, 2017) where words such as "madness" and "sorcery" are used to describe dementia symptoms (Labinjo et al., 2020). Furthermore, these stigmatizing words, however potent, emerged due to the sociocultural meaningmaking process in Nigerian communities (Kleinman, 1978 ) and poor scientific or clinical dementia knowledge (Nwakasi, 2019; Nwakasi et al., 2019). Furthermore, the deep cultural roots of these stigmatizing views about dementia which were also held by some educated Nigerians points to the challenges in addressing dementia-related issues effectively (Spittel et al., 2019), thus stressing the need for systematic dementia sensitization and awareness campaigns in Nigeria.

Another interesting finding was that for some of the participants, being caregivers allowed them to protect their relatives and shield themselves and other members of their families from outsiders' negative attitudes - the attitudes which may constitute stigmatization. This protection which is a behavioral reaction is reasonable given that some dementia behaviors are viewed as embarrassing and damaging to a person's reputation (Hall \& Sikes, 2017). Nigerian caregivers put up a protective approach to "safeguard" their loved ones from stigmatization within the community. This stigma is often a product of a dynamic, multifaceted social process that can consistently lead to poor outcomes for people living with mental health conditions and those caring for them (Shamsaei et al., 2013). More so, while providing this type of protection from stigma for their relatives, these caregivers may not seek specialized supports that are helpful for caregiving and the management of severe and life-threatening progression of dementia (Nwakasi, 2019; Ogunniyi, 2018). 
The study also found that negative attitudes about dementia from family members can have a profound impact on care, especially when some family members refuse to provide support or cease to communicate with relatives with dementia due to fear of stigmatization. This is similar to another study that found that caregivers' stigma from $\mathrm{AD}$ resulted in caregivers concealing the diagnosis and the person with $\mathrm{AD}$ from outsiders, and reduced caregiving for the person with $\mathrm{AD}$ (Werner et al., 2010). Ae-Ngibise et al. (2015) described a similar situation that resulted in "lack of support from others" and "diminished social relationships." Sometimes, the withdrawal of support from some family members may result from pejorative views of the family (e.g., with dementia) by the public - these views may go as far as people refusing to marry into families of people living with dementia (Adebiyi et al., 2016). Therefore, it may be unsurprising that some family members would want to dissociate themselves from their relatives living with dementia to protect their social relationships and standing in the community (Kehoua et al., 2019).

Negative attitudes about dementia symptoms (e.g., madness, sorcery), especially those that are stigmatizing, can affect access to dementia caregiving support as caregivers may be reluctant to seek for help, or if they do, they may not get the help they need. When these happen, the burden from dementia caregiving is worsened as well as the quality of care the person with dementia receives. For these caregivers to effectively provide care, they require access to a combination of family support, community-based informal support, and government formal support (Chow et al., 2010).

\section{Implications}

Nigeria needs policies to raise dementia awareness and to help protect the dignities and well-being of older Nigerians living with dementia and their caregivers. A U.K. study found that involving schools in dementia programs increased dementia awareness, reduced stigma, increased knowledge on how to support caregivers, and a better understanding of the challenges people with dementia and their caregivers face (Atkinson \& Bray, 2013). In South Africa, some non-governmental organizations created public awareness on mental health and reduced associated stigmas through media campaigns, school talks, rural outreach, counseling services, and also by providing information resource centers to the public (Kakuma et al., 2010). A Nigerian study identified the need for more mental health stigma advocacy, participation from government agencies to fund and help combat stigma, and creation of education and information programs to improve attitudes about people with mental illness (Armiyau, 2015). These approaches are worthy of consideration to be widely replicated in Nigeria to address poor dementia knowledge and reduce the associated stigma.

Religious practices are helpful in increasing coping and mitigating caregiving stress (Harris et al., 2013), and as Nigerians are quite religious, this medium can be explored to combat dementia stigma. Christian and Islamic organizations such as churches and mosques can be used to promote dementia awareness and reduce stigma in Nigeria. For example, a study found that African American churches can be used in mental health campaigns and clergies serve as gatekeepers for access to mental health services in the community (Williams et al., 2014). More importantly, by training church leaders and clergies, some families with persons living with dementia will have access to appropriate dementia and caregiving information when they seek support from their religious organizations in their communities. In addition, unorthodox healers and indigenous religious leaders in Nigeria are an untapped group of stakeholders in promoting mental health and well-being. Collaborations between orthodox and unorthodox medical practitioners may result in increased access to mental health services in Nigerian communities (Burns \& Tomita, 2015) — such collaborations can also be harnessed to improve dementia knowledge, referrals, and access to specialized caregiving support.

\section{Limitations}

The study has some limitations. The caregivers were interviewed only once and as a result, some of the compelling views they shared were not probed further. Nonetheless, using FGs ensured some of these views were further explored for more insight, therefore, strengthening the trustworthiness of the study. Conducting the interviews with the caregivers over the phone was a way to help minimize the effect of dementia-related stigma on data collection. For example, caregivers may be uncomfortable with sharing their views about dementia symptoms and their caregiving experiences during face-to-face interviews, but they may feel less discomfort doing so over the phone with more anonymity. However, using phone interviews makes identifying relevant participants' expressions (e.g., body language, facial expressions) difficult.

\section{Conclusion}

This study explored attitudes about dementia and caregiving in Nigeria. In addition to Nigeria's rapid aging, increasing risk of dementia, and poor health system, this study is also based on the premise that Nigerian women are at the center of informal long-term care in Nigeria. Therefore, understanding how negative attitudes (e.g., stigmatizing views) about dementia impacts 
the experiences of these dementia caregivers may be important for policymakers and other stakeholders in Nigeria's health care and social services sectors. Increasing dementia education through channels such as advocacy programs aired over the radio, and dementia awareness collaborations with religious organizations may help reduce the impact of dementia stigma in the country. Furthermore, there is need for policies that focus on supporting dementia caregivers (i.e., the women) as their quality of life and that of persons with dementia may depend on such interventions.

\section{Declaration of Conflicting Interests}

The authors declared no potential conflicts of interest with respect to the research, authorship, and/or publication of this article.

\section{Funding}

The authors disclosed receipt of the following financial support for the research, authorship, and/or publication of this article: Self-funded.

\section{ORCID iD}

Candidus C. Nwakasi iD https://orcid.org/0000-0001-5727-1694

\section{Supplemental Material}

Supplemental Material for this article is available online at journals.sagepub.com/home/qhr.

\section{References}

Abdulmalik, J., Olayiwola, S., Docrat, S., Lund, C., Chisholm, D., \& Gureje, O. (2019). Sustainable financing mechanisms for strengthening mental health systems in Nigeria. International Journal of Mental Health Systems, 13, Article 38. https://doi.org/10.1186/s13033-019-0293-8

Adebiyi, A. O., Fagbola, M. A., Olakehinde, O., \& Ogunniyi, A. (2016). Enacted and implied stigma for dementia in a community in south-west Nigeria. Psychogeriatrics, 16(4), 268-273. https://doi.org/10.1111/psyg.12156

Adeloye, D., Auta, A., Ezejimofor, M., Oyedokun, A., Harhay, M. O., Rudan, I., \& Chan, K. Y. (2019). Prevalence of dementia in Nigeria: A systematic review of the evidence. Journal of Global Health Reports, 3, Article e2019014. https://doi/10.29392/joghr.3.e2019014

Ae-Ngibise, K. A., Doku, V. C. K., Asante, K. P., \& OwusuAgyei, S. (2015). The experience of caregivers of people living with serious mental disorders: A study from rural Ghana. Global Health Action, 8(1), Article 26957. https:// doi.org/10.3402/gha.v8.26957

Akinyemi, A. (2014). Ageing and national development in Nigeria: Costly assumptions and challenges for the future. https://www.researchgate.net/publication/289428065 Ageing_and_national_development_in_Nigeria_Costly_ assumptions_and_challenges_for_the_future
Armiyau, A. Y. (2015). A review of stigma and mental illness in Nigeria. https://www.researchgate.net/profile/Aishatu_ Armiyau2/publication/277934187 A Review of Stigma and_Mental_Illness_in_Nigeria/links/57c8 $\overline{4} 29 \overline{\mathrm{f}} 08 \mathrm{aefc} \overline{4}$ af34-be6c.pdf

Atkinson, T., \& Bray, J. (2013). Dementia awareness \& intergenerational exchange in schools: A pioneer project supporting dementia friendly communities. https://www2. worcester.ac.uk/documents/Schools_Evaluation_Final Report.pdf

Ballard, C., Gauthier, S., Corbett, A., Brayne, C., Aarsland, D., \& Jones, E. (2011). Alzheimer's disease. The Lancet, 377(9770), 1019-1031. https://doi.org/10.1016/S01406736(10)61349-9

Benbow, S. M., \& Jolley, D. (2012). Dementia: Stigma and its effects. Neurodegenerative Disease Management, 2(2), 165-172. https://doi.org/10.2217/nmt.12.7

Berwald, S., Roche, M., Adelman, S., Mukadam, N., \& Livingston, G. (2016). Black African and Caribbean British communities' perceptions of memory problems: "We don't do dementia." PLOS ONE, 11(4), Article e0151878. https:// doi.org/10.1371/journal.pone.0151878

Birks, M., Chapman, Y., \& Francis, K. (2008). Memoing in qualitative research: Proving data and processes. Journal of Research in Nursing, 13(1), 68-75. https://doi. org/10.1177/1744987107091254

Birt, L., Scott, S., Cavers, D., Campbell, C., \& Walter, F. (2016). Memberchecking: A tool to enhance trustworthiness ormerely a nod to validation? Qualitative Health Research, 26(13), 1802-1811. https://doi.org/10.1177/1049732316654870

Braun, V., \& Clarke, V. (2006). Using thematic analysis in psychology. Qualitative Research in Psychology, 3, 77-101. https://doi.org/10.1191/1478088706qp063oa

Brinkhoff, T. (2017). Anambra: State in Nigeria. https:// www.citypopulation.de/php/nigeria-admin.php?adm $1 \mathrm{id}=$ NGA004

Brooke, J., \& Ojo, O. (2019). Contemporary views on dementia as witchcraft in sub-Saharan Africa: A systematic review. Journal of Clinical Nursing, 29, 20-30. https://doi. org/10.1111/jocn.15066

Bryman, A. (2012). Social research methods (4th ed.). Oxford University Press.

Burns, J. K., \& Tomita, A. (2015). Traditional and religious healers in the pathway to care for people with mental disorders in Africa: A systematic review and meta-analysis. Social Psychiatry and Psychiatric Epidemiology, 50(6), 867-877. https://doi.org/10.1007/s00127-014-0989-7

Chow, J. C. C., Auh, E. Y., Scharlach, A. E., Lehning, A. J., \& Goldstein, C. (2010). Types and sources of support received by family caregivers of older adults from diverse racial and ethnic groups. Journal of Ethnic \& Cultural Diversity in Social Work, 19(3), 175-194. https://doi.org/10.1080/153 13204.2010.499318

Dilworth-Anderson, P., \& Gibson, B. E. (2002). The cultural influence of values, norms, meanings, and perceptions in understanding dementia in ethnic minorities. Alzheimer Disease \& Associated Disorders, 16, S56-S63. https://doi. org/10.1097/00002093-200200002-00005 
Faleye, O. A. (2017). Housing "lunatics" in Nigeria: A study in the history of eco-psychiatry and psychiatric epidemiology. https://pdfs.semanticscholar.org/1bc6/acad09eb4 $6004 \mathrm{c} 4 \mathrm{f} 4578900 \mathrm{a} 8 \mathrm{~b} 78 \mathrm{ff} 567610$.pdf? ga=2.5922099. 1297575420.1572128597-1052156134.1570034953

Fereday, J., \& Muir-Cochrane, E. (2006). Demonstrating rigor using thematic analysis: A hybrid approach of inductive and deductive coding and theme development. International Journal of Qualitative Methods, 5(1), 80-92. https://doi. org/10.1177/160940690600500107

Fusch, P. I., \& Ness, L. R. (2015). Are we there yet? Data saturation in qualitative research. The Qualitative Report, 20(9), 1408-1416. http://nsuworks.nova.edu/tqr/vol20/iss9/3

George-Carey, R., Adeloye, D., Chan, K. Y., Paul, A., Kolčić, I., Campbell, H., \& Rudan, I. (2012). An estimate of the prevalence of dementia in Africa: A systematic analysis. Journal of Global Health, 2(2), Article 020401. https://doi. org/10.7189/jogh.02.020401

Goffman, E. (1963). Stigma: Notes on the management of spoiled identity. Prentice-Hall.

Goffman, E. (2006). Selections from stigma. In L. E. Davis (Ed.), The disability studies reader (2nd ed., pp. 131-140). Routledge.

Gurayah, T. (2015). Caregiving for people with dementia in a rural context in South Africa. South African Family Practice, 57(3), 194-197. https://doi.org/10.1080/2078619 0.2014 .976946

Hadi, M., A., \& Closs, S., J. (2015). Ensuring rigour and trustworthiness of qualitative research in clinical pharmacy. International Journal of Clinical Pharmacy, 38, 641-646.

Hall, M., \& Sikes, P. (2017). "It would be easier if she'd died": Young people with parents with dementia articulating inadmissible stories. Qualitative Health Research, 27(8), 1203-1214. https://doi.org/10.1177/1049732317697079

Hamilton, J. B. (2020). Rigor in qualitative methods: An evaluation of strategies among underrepresented rural communities. Qualitative Health Research, 30(2), 196-204. https:// doi.org/10.1177/1049732319860267

Harris, G. M., Allen, R. S., Dunn, L., \& Parmelee, P. (2013). "Trouble won't last always": Religious coping and meaning in the stress process. Qualitative Health Research, 23(6), 773-781. https://doi.org/10.1177/1049732313482590

He, W., Goodkind, D., \& Kowal, P. (2016). An aging world: 2015. https://www.census.gov/content/dam/Census/library /publications/2016/demo/p95-16-1.pdf

Kakuma, R., Kleintjes, S., Lund, C., Drew, N., Green, A.,Flisher, A. J. \& MHAPP Research Programme Consortium. (2010). Mental health stigma: What is being done to raise awareness and reduce stigma in South Africa? African Journal of Psychiatry, 13(2), 116-124. https://doi.org/10.4314/ajpsy. v13i2.54357

Kalaria, R. N., Maestre, G. E., Arizaga, R., Friedland, R. P., Galasko, D., Hall, K., . . . Antuono, P. (2008). Alzheimer's disease and vascular dementia in developing countries: Prevalence, management, and risk factors. The Lancet Neurology, 7(9), 812-826. https://doi.org/10.1016/S14744422(08)70169-8

Kehoua, G., Dubreuil, C. M., Ndamba-Bandzouzi, B., Guerchet, M., Mbelesso, P., Dartigues, J. F., \& Preux, P. M. (2019).
People with dementia in Sub-Saharan Africa: From support to abuse by caregivers: Results of EPIDEMCA-FU program in Congo. Dementia and Geriatric Cognitive Disorders Extra, 9(1), 163-175. https://doi/10.1159/000489846

Khonje, V., Milligan, C., Yako, Y., Mabelane, M., Borochowitz, K. E., \& de Jager, C. A. (2015). Knowledge, attitudes and beliefs about dementia in an urban Xhosa-speaking community in South Africa. Advances in Alzheimer's Disease, 4, 21-36. https://doi.org/10.4236/aad.2015.42004

Kim, H., Sefcik, J. S., \& Bradway, C. (2017). Characteristics of qualitative descriptive studies: A systematic review. Research in Nursing \& Health, 40(1), 23-42. https://doi. org/10.1002/nur.21768

Kleinman, A. (1978). Concepts and a model for the comparison of medical systems as cultural systems. Social Science and Medicine. Part B: Medical Anthropology, 12, 85-93. https://doi.org/10.4324/9781003136378-3

Kleinman, A., \& Good, B. (Eds.). (1985). Culture and depression: Studies in anthropology and cross-cultural psychiatry of affect and disorder. University of California Press.

Labinjo, T., Serrant, L., Ashmore, R., \& Turner, J. (2020). Perceptions, attitudes and cultural understandings of mental health in Nigeria: A scoping review of published literature. Mental Health, Religion \& Culture, 23(7), 606-624. https://doi.org/10.1080/13674676.2020.1726 883

Lambert, S. D., \& Loiselle, C. G. (2008). Combining individual interviews and focus groups to enhance data richness. Journal of Advanced Nursing, 62(2), 228-237. https://doi. org/10.1111/j.1365-2648.2007.04559.x

Lambert, V. A., \& Lambert, C. E. (2012). Qualitative descriptive research: An acceptable design. Pacific Rim International Journal of Nursing Research, 16(4), 255-256. https://he02. tci-thaijo.org/index.php/PRIJNR/article/view/5805

Lietz, C. A., Langer, C. L., \& Furman, R. (2006). Establishing trustworthiness in qualitative research in social work. Qualitative Social Work, 5(4), 441-458. https://doi. org/10/1177/1473325006070288

Liu, D., Hinton, L., Tran, C., Hinton, D., \& Barker, J. C. (2008). Reexamining the relationships among dementia, stigma, and aging in immigrant Chinese and Vietnamese family caregivers. Journal of Cross-Cultural Gerontology, 23(3), 283-299. https://doi.org/10.1007/s10823-008-9075-5

Nwakasi, C. C. (2019). Exploring the experiences of Nigerian female dementia caregivers [Electronic thesis or dissertation]. https://etd.ohiolink.edu/apexprod/rws_olink/r/1501 $/ 10$ ?p10_etd_subid $=183263 \&$ clear $=10$

Nwakasi, C. C., Hayes, C., Fulton, J., \& Roberts, A. R. (2019). A pilot qualitative study of dementia perceptions of Nigerian migrant caregivers. International. Journal of Africa Nursing Sciences, 10, 167-174. https://doi.org/10.1016/j. ijans.2019.03.003

Ogunniyi, A. (2018). Challenges faced by Nigerian families dealing with dementia: What can be done? http:// gabiwilliamsalzheimersfoundation.org/assets/img/demo/ GWAF\%20lecture_2018.pdf

Ogunniyi, A., Hall, K. S., Baiyewu, O., Gureje, O., Unverzagt, F., Gao, S., \& Hendrie, H. C. (2005). Caring for individuals with dementia: The Nigerian experience. West 
African Journal of Medicine, 24(3), 259-262. https://doi. org/10.4314/wajm.v24i3.28211

Okoye, U. (2012). Family care-giving for ageing parents in Nigeria: Gender differences, cultural imperatives and the role of education. https://www.researchgate.net/publication /233762967_Family_care-giving_for_ageing_parents_in Nigeria_gender_differences_cultural_imperatives_and_the_ role_of_education

Okoye, U. (2014). Financial incentives to support family caregivers of older adults in Nigeria: A policy consideration. https://www.researchgate.net/publication/267868227_ Financial_Incentives_to_Support_Family_Care-Givers_ of_Older_Adults_in_Nigeria_a_Policy_Consideration

Pescosolido, B., \& Martin, J. K. (2015). The stigma complex. Annual Review of Sociology, 41, 87-116. https://doi. org/10.1146/annurev-soc-071312-145702

Sandelowski, M. (2000). Whatever happened to qualitative description? Research in Nursing \& Health, 23(4), 334-340. https://doi.org/10.1002/1098-240x(200008)23:4<334::aidnur9>3.0.co; $2-\mathrm{g}$

Schatz, E., \& Seeley, J. (2015). Gender, ageing and carework in East and Southern Africa: A review. Global Public Health, 10(10), 1185-1200. https://doi.org/10.1080/17441692.201 5.1035664

Shamsaei, F., Kermanshahi, S. M. K., Vanaki, Z., \& Holtforth, M. G. (2013). Family care giving in bipolar disorder: Experiences of stigma. Iranian Journal of Psychiatry, 8(4), 188-194. https://pubmed.ncbi.nlm.nih.gov/25628713/

Sosa-Ortiz, A. L., Acosta-Castillo, I., \& Prince, M. J. (2012). Epidemiology of dementias and Alzheimer's disease. Archives of Medical Research, 43(8), 600-608. https://doi. org/10.1016/j.arcmed.2012.11.003

Spittel, S., Maier, A., \& Kraus, E. (2019). Awareness challenges of mental health disorder and dementia facing stigmatisation and discrimination: A systematic literature review from Sub-Sahara Africa. Journal of Global Health, 9(2), 1-11. https://doi/10.7189/jogh.09.020419

Togonu-Bickersteth, F., \& Akinyemi, A. I. (2014). Ageing and national development in Nigeria: Costly assumptions and challenges for the future. African Population Studies, 27(2), 361-371. https://doi.org/10.11564/27-2-481

Ugochukwu, O., Mbaezue, N., Lawal, S. A., Azubogu, C., Sheikh, T. L., \& Vallières, F. (2020). The time is now: Reforming Nigeria's outdated mental health laws. The Lancet. Global Health, 8(8), e989-e990. https://doi.org /10.1016/S2214-109X(20)30302-8

Urbańska, K., Szcześniak, D., \& Rymaszewska, J. (2015). The stigma of dementia. Postępy Psychiatrii i Neurologii, 24(4), 225-230. https://doi.org/10.1016/j.pin.2015.10.001

Uwakwe, R. (2000). Knowledge of religious organizations about dementia and their role in care. International Journal of Psychiatry, 15, 1152-1157. https://doi.org/10.1002/10991166(200012)15:12<1152::aid-gps247>3.0.co;2-m

Uwakwe, R. (2006). Satisfaction with dementia care-giving in Nigeria-A pilot investigation. International Journal of Geriatric Psychiatry, 21(3), 296-297. https://doi.org /10.1002/gps. 1500

Velkoff, V. A., \& Kowal, P. R. (2006). Aging in sub-Saharan Africa: The changing demography of the region. http:// www.nap.edu/read/11708/chapter/5\#55

Wahab, E. O., \& Ikebudu, C. J. (2014). Quality of life of patients with early onset dementia in Nigeria. International Letters of Social and Humanistic Sciences, 12, 28-42. https://doi.org/10.18052/www.scipress.com/ ILSHS. 12.28

Welcome, M. O. (2011). The Nigerian health care system: Need for integrating adequate medical intelligence and surveillance systems. Journal of Pharmacy \& Bioallied Sciences, 3(4), 470-478. https://doi.org/10.4103/09757406.90100

Werner, P., Goldstein, D., \& Buchbinder, E. (2010). Subjective experience of family stigma as reported by children of Alzheimer's disease patients. Qualitative Health Research, 20(2), 159-169. https://doi.org/10.1177/1049 732309358330

Williams, L., Gorman, R., \& Hankerson, S. (2014). Implementing a mental health ministry committee in faith-based organizations: The promoting emotional wellness and spirituality program. Social Work in Health Care, 53(4), 414-434. https://doi.org/10.1080/00981389.2014.880391

World Health Organization. (2014). Mental health atlas country profile 2014: Nigeria. https://www.who.int/mental_health/ evidence/atlas/profiles-2014/nga.pdf?ua $=1$

Yusuf, A. J., \& Baiyewu, O. (2012). Beliefs and attitudes towards dementia among community leaders in northern Nigeria. West African Journal of Medicine, 31(1), 3-7. https:// www.researchgate.net/publication/232745751_Beliefs and_Attitudes_Towards_Dementia_among_Community_ Leaders in_Northern_Nigeria

Zaney, G. D. (2018). Promoting a healthier, secure aging. http://www.ghana.gov.gh/index.php/media-center/ features/1966-promoting-a-healthier-secure-ageing

\section{Author Biographies}

Candidus C. Nwakasi, $\mathrm{PhD}$, is an assistant professor of Health Policy and Management at Providence College, Rhode Island, US. His research interests include examining factors influencing care access and health in disadvantaged population groups (e.g., older adults, immigrants, inmates).

Kate de Medeiros, $\mathrm{PhD}$, is a professor of Gerontology in the Department of Sociology and Gerontology at Miami University, Oxford, Ohio, US. Her dementia-related research includes the meaning of place and friendships in long-term care, self and personhood, and the role of the participatory arts.

Foluke S. Bosun-Arije, $\mathrm{PhD}$, is a registered nurse, and a senior lecturer in the Department of Nursing, Manchester Metropolitan University, UK. Her research interests include management of Non-Communicable Diseases (NCDs) with a particular interest in the remission and management of Type 2 Diabetes mellitus. 